\title{
Actual daily evapotranspiration estimated from MERIS and AATSR data over the Chinese Loess Plateau
}

\author{
R. Liu, J. Wen, X. Wang, L. Wang, H. Tian, T. T. Zhang, X. K. Shi, J. H. Zhang, and SH. N. Lv \\ Laboratory of Climate Environment and Disasters of Western China, Cold and Arid Regions Environmental and Engineering \\ Research Institute, Chinese Academy of Sciences, Lanzhou, Gansu 730000, China
}

Received: 25 December 2008 - Published in Hydrol. Earth Syst. Sci. Discuss.: 23 February 2009

Revised: 21 October 2009 - Accepted: 6 November 2009 - Published: 11 January 2010

\begin{abstract}
The Chinese Loess Plateau is located in the north of China and has a significant impact on the climate and ecosystem evolvement over the East Asian continent. Estimates of evapotranspiration (ET) at a regional scale are in crucial need for climate studies, weather forecasts, hydrological surveys, ecological monitoring and water resource management. In this research, the ET of the Chinese Loess Plateau was estimated by using an energy balance approach and data collected during the LOess Plateau land-atmosphere interaction pilot EXperiments 2005 (LOPEX05). With the combined data of the Medium Resolution Imaging Spectrometer (MERIS), the Advanced Along-Track Scanning Radiometer (AATSR) and some other variables such as air temperature, crop height and wind speed, the instantaneous net radiation, sensible heat flux and soil heat flux were calculated; the instantaneous latent heat flux was derived as the residual term of energy balance, and then converted to daily ET value by sunshine duration. The calculated daily ET from the model showed a good match with the measurements of the eddy covariance systems deployed in LOPEX05. The minimum relative error of this approach is $9.0 \%$, the cause of the bias was also explored and discussed.
\end{abstract}

\section{Introduction}

Evaporation is the process of water changing from a liquid state into a gas or vapor state, transpiration is the evaporation of water from a plant's leaves, stem, flowers or roots back into the atmosphere. Evapotranspiration (ET), the sum of water lost to the atmosphere from the soil surface through evaporation and from plant tissues via transpiration, is a vital component of the terrestrial water cycle, which includes

Correspondence to: J. Wen

(jwen@1zb.ac.cn) precipitation, runoff, streamflow, soil-water storage and ET. Agriculture alone in China accounts for 70\% of the nation's consumptive water usage (Huang, 2001). Crop yield decreases if irrigation and rainfall amounts are not equal to ET, while excessive irrigation may cause percolation of water along with agri-chemicals below vadoze zone. Accurate ET estimation over large areas will provide valuable assistance to efficient water usage and irrigation management, especially nowadays when there is increasing demand and shortage of water resources (Seckler et al., 1999). However, the ET is usually difficult to achieve because it is not a variable measured directly.

Over the pasted years, several methods have been proposed to estimate ET for a wide range of surface conditions and spatial or temporal scales. Most of these are variations of Penman's equation (Allen et al., 1998) and Priestley-Taylor's equation (Priestley and Taylor, 1972). These models have been widely applied and yield various results. However, these models require numerous meteorology variables (such as air temperature, relative humidity, wind speed and solar radiation), which usually come from very sparse distribution of meteorological stations.

With the advance of ground observation and turbulent flux monitoring technology, the routinely estimating ET is a potential from point data of operational weather station to a wide scale area by satellite remote sensing measurements. Remote sensing has proven to be the only suitable approach for large-area ET estimates, because satellite remote sensing is the only technology that can provide parameters such as radiometric surface temperature, albedo, and vegetation index at a globally consistent and economically feasible manner. The main advantage of remote sense data, is that large areas of information is easily obtainable without extensive monitoring fieldwork. Moreover, advancements in sensors, improved retrieval algorithms and tremendous increases in data distribution, storage and processing have greatly promoted the utilization of remote sensing data in estimating

Published by Copernicus Publications on behalf of the European Geosciences Union. 
ET. The ET is mainly controlled by the available energy, the surface-air temperature difference, the relative humidity, and precipitation. In the past decades, many algorithms using remote sensing information to estimate ET have been developed, and from simple and empirical approaches to complex and data consuming ones. These can be put into two groups broadly: (1) to estimate ET by set empirical relation between ET and parameters (vegetation index, temperature, albedo) that could be measured from meteorological satellites (Index, 1994; Boegh, 2002; McCabe et al., 2005); (2) to calculate the sensible heat flux first and then obtain the latent heat flux as the residual of the energy balance equation, SEBAL (Bastiaanssen et al., 1998), SEBS (Su et al., 1999; Su, 2002), NTDI (McVicar and Jupp, 1999). Most models require a complex and high-quality input data to obtain accurate results and each method has limitations (Bashir et al., 2008). Vegetation index-based scaling method relies on foliage density as the main independent variable, they do not adequately account for direct evaporation from soil or leaves following rainfall events. Different limiting factors for ET apply in different ecosystems, and they cannot capture ET changes at hourly scales or days needed to model ET as a function of micrometeorological conditions over the course of a day (Glenn et al., 2007). Surface temperature combined with spatially constant surface meteorological parameters may be suitable for assessing the surface fluxes on a small scale, but they failed for large scales where the surface meteorological parameters are no longer constant, and the surface geometrical and thermal conditions are neither homogenous nor constant any more (Su et al., 2003). Probably, the most practical solution is estimating instantaneous values from energy balance models combined with sun synchronous observations (Hoedjes et al., 2008). Since the 1980s, energy balance methods have been the preferred method for estimating wide-area ET in the remote sensing community (Overgaard et al., 2006).

The ET of the Loess Plateau, is well related to the surface soil moisture content, and also has a significant impact on the water resources in eastern Asia. Although successful estimations of the ET have been obtained over small-scale homogeneous surfaces, difficulties remain in estimating partial canopies which are geometrically and thermally heterogeneous over the Chinese Loess Plateau (Zhang et al., 2005; Chen et al., 2005).

The objective of the presented research here is to propose a simple algorithm to improve the daily ET estimates by using multi-sensor remote sensing measurements. The proposed methodology is intended to avoid numerous surface meteorological observations that are not readily available over large areas. All the data were collected during an experimental campaign carried out in the summer of 2005, encompassing all the stages in the corn growing season, from the beginning of July (cob formation) to the end of August (plant mature). The estimated instantaneous energy complements and daily ET were presented and validated by using ground measurements. The final results were analyzed and discussed.

\section{Methodology}

\subsection{Estimate of the instantaneous ET}

Near surface net radiation is the balance of the up-welling and down-welling streams of shortwave and long-wave radiation, which is the fundamental source quantity of energy balance at the Earth's surface. Most ET models require $R_{n}$ as the essential input parameter, and an accurate estimation of $R_{n}$ is essential for regional water resource management (Ryu et al., 2008). The evaporation or ET $\left(\mathrm{mm} \mathrm{s}^{-1}\right)$ is the water amount transferred from land surface to atmosphere, while the latent heat flux $\left(\mathrm{W} \mathrm{m}^{-2}\right)$ is the energy consumed by evaporating or transporting water from land or vegetation surface to the atmosphere. As the sum of latent heat flux $(L E)$, sensible heat flux $(H)$, and surface soil heat flux $(G)$ (neglecting other storage terms), $R_{n}$ is the source energy of landatmosphere exchange in the land surface process. The energy balance equation is given by the following equation

$L E=R_{n}-H-G$

where $R_{n}$ is the net radiation $\left(\mathrm{W} \mathrm{m}^{-2}\right), H$ is the sensible heat flux $\left(\mathrm{W} \mathrm{m}^{-2}\right)$ and $G$ is the soil heat flux $\left(\mathrm{W} \mathrm{m}^{-2}\right) ; L E$ is the latent heat flux, which is measured in energy units $\left(\mathrm{W} \mathrm{m}^{-2}\right), E$ is identical to evapotranspiration, which is measured in water column units ( $L$ is latent heat of vaporization, $\left.2.49 \times 10^{6} \mathrm{~J} \mathrm{~kg}^{-1}\right)$. The partitioning of the different fluxes into bare soil surface and corn canopy was accomplished according to the scheme shown in Fig. 1. According to this configuration, the componential fluxes to total latent heat flux can be written as:

$$
\begin{aligned}
& L E=L E_{v}+L E_{g} \\
& L E_{v}=R_{n v}-H_{v}-G_{v} \\
& L E_{g}=R_{n g}-H_{g}-G_{g}
\end{aligned}
$$

where $R_{n v}$ is the net radiation over the vegetation canopy; $R_{n g}$ is the net radiation over the soil surface; $H_{v}$ and $H_{g}$ are the contributions of the canopy and soil to the total sensible heat flux. $G_{v}$ is the soil heat flux for the soil beneath the canopy and $G_{g}$ is the soil heat flux of the bare soil surface. Thus, the $L E$ over the whole area can be partitioned into soil and canopy components, respectively.

\subsubsection{The net radiation over the canopy and the bare soil surface}

In digital satellite imagery, each pixel usually represents a large area on the ground. Thus, it is possible that a pixel is a mixture of several typical ground objects in proportions. How to decompose the mixed pixels precisely and effectively for multi-spectral remote sensing images is a critical issue for a quantitative research. Therefore, this paper provides a holistic systematic approach: separate the contribution of 


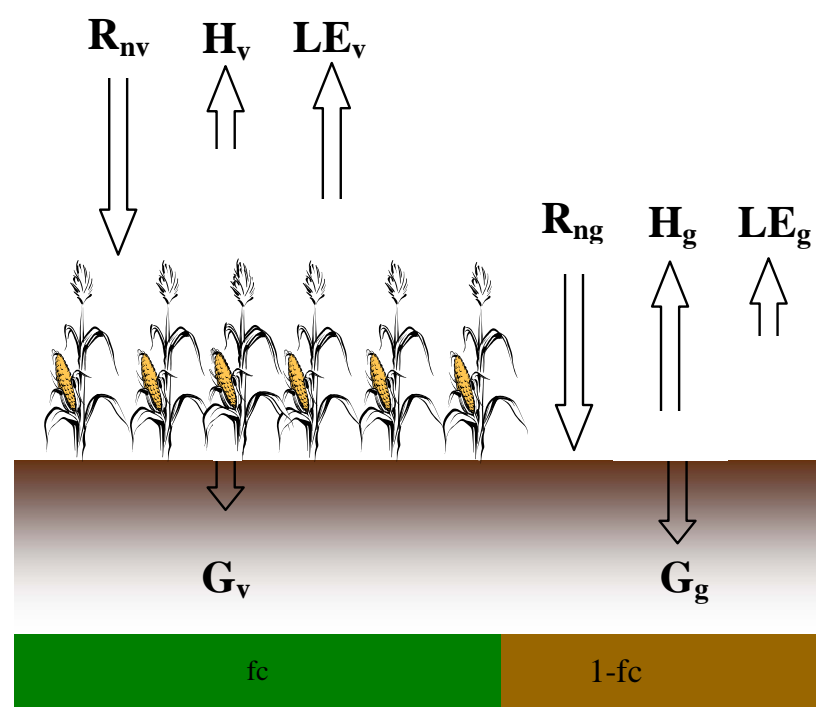

Fig. 1. Scheme of flux partition for soil and canopy. Symbols are defined in the text.

vegetation canopy and ground from the mixed pixel. To be consistent with the configuration, a partitioning of the net radiation flux, $R_{n}$ for the soil and canopy is proposed as follows

$R_{n}=f_{v} R_{n v}+\left(1-f_{v}\right) R_{n g}$

where $R_{n v}$ and $R_{n g}$ are contributions of the canopy and soil to the total net radiation flux, respectively. The vegetation fraction is expressed according to $f_{v}=\frac{\mathrm{NDVI}-\mathrm{NDVI}_{\min }}{\mathrm{NDVI}_{\max }-\mathrm{NDVI}_{\min }}$ (Gutman and Ignatov, 1998). $\mathrm{NDVI}_{\min }$ corresponds to the

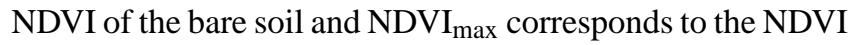
of the full vegetation after the atmospheric corrections. The accuracy of $f_{v}$ estimate from this relationship is acceptable for moderate vegetation coverage condition, but poor for the extreme low vegetation coverage or high vegetation coverage conditions.

The net radiation is given by the following equation

$R_{n}=(1-\alpha) Q+L \downarrow-L \uparrow$

where $\alpha$ is the surface albedo, and can be elicited by SMAC model and satellite remote sensing data; $Q$ is the solar global radiation $\left(\mathrm{W} \mathrm{m}^{-2}\right)$. The land surface albedo was derived from SMAC and MERIS data, it was portioned by the vegetation fractional coverage and the typical discrepancy between soil and canopy surface albedo, these were

$\alpha_{v}=\alpha_{s}-\left(1-f_{v}\right) \delta \alpha$

$\alpha_{g}=\alpha_{s}+f_{v} \delta \alpha$

where $\alpha_{s}$ was the surface albedo of a mixed pixel derived from satellite remote sensing data; $\alpha_{g}$ was the albedo above the bare soil surface; $\alpha_{v}$ was the albedo above the canopy surface; $\delta \alpha$ was the typical discrepancy between the soil and canopy surface albedo (0.1 was taken in this research).
$L \downarrow$ is the downward long-wave radiation $\left(\mathrm{W} \mathrm{m}^{-2}\right)$, and can be obtained by the ground observation data from the weather station when ignoring the effect of cloud (Holtslag and Vanulden, 1983)

$L \downarrow=5.31 \times 10^{-13} T_{a}^{6}$

where $T_{a}$ (in unit Kelvin degree, $\mathrm{K}$ ) is the air temperature over canopy or bare soil. Since the temperature sensor was mounted at $2.9 \mathrm{~m}$ height during the experiment, then, the measured air temperature can represent the mean temperatures over the cornfield and fallow farmland.

$L \uparrow$ is the outgoing long-wave radiation flux density $\left(\mathrm{W} \mathrm{m}^{-2}\right.$ ) governed by the surface temperature by the StefanBoltzmann law

$L \uparrow=\varepsilon \sigma T_{s}^{4}$

where $\varepsilon=1.0094 \times 0.047 \ln$ (NDVI) (Pang et al., 2004) is the land surface effective emissivity; $\sigma$ is the Stefan-Boltzmann constant $\left(5.669 \times 10^{-8} \mathrm{~W} \mathrm{~m}^{-2} \mathrm{k}^{-4}\right) ; T_{S}$ is the land surface temperature $(\mathrm{K})$. The split-window $(\mathrm{SW})$ algorithm can minimize the contributions of water vapour in land surface retrieval and the AATSR have two thermal channels. Therefore, the surface temperatures were calculated by splitwindow algorithm, and it was portioned by the vegetation fractional coverage and the typical discrepancy between soil and canopy surface temperature (Li et al., 2001; Menenti et al., 2001; Jia et al., 2003), these were

$T_{v}=T_{s}-\left(1-f_{v}\right) \delta T$

$T_{g}=T_{s}+f_{v} \delta T$

where $T_{S}$ was the surface temperature derived from SW and AATSR data; $T_{g}$ was the temperature above the bare soil surface; $T_{v}$ was the temperature above the canopy surface; $\delta T$ was the typical discrepancy between soil and canopy surface temperature, which depends on the field and density of vegetation, and moisture status ( $\mathrm{Li}$ et al., 2001; Menenti et al., 2001; Jia et al., 2003), a $2.3 \mathrm{~K}$ was observed during the experiment at the satellite overpass time.

\subsubsection{The near surface sensible heat flux}

The near surface sensible heat flux is the heat that is initially transferred to the near surface atmosphere by conduction and to the bulk atmosphere by convection, calculated according to the following equation (Spittlehouse and Black, 1980)

$H=\rho C p\left(T_{s}-T_{a}\right) / r_{a}$

where $\rho$ is the air density; $C p$ is the specific heat capacity of air, in the Chinese Loess Plateau, the air pressure $P$ is $87 \mathrm{kPa}$ in daytime (measured by the automatic weather station), $R$ is $287.05 \mathrm{~J} \mathrm{~kg}^{-1} \mathrm{~K}^{-1}, T$ is $300 \mathrm{~K}$ approximately (measured by EC), $C p$ is $1004 \mathrm{~J} \mathrm{~kg}^{-1} \mathrm{~K}^{-1}$. According to the equation of state $P=\rho R T$, the value of $\rho C p$ is $1015 \mathrm{~J} \mathrm{~kg}^{-1} \mathrm{~K}^{-1} ; r_{a}$ 
is aerodynamic resistance. To be consistent with the model configuration, a partitioning of the sensible heat flux, $H$, between the soil and canopy is proposed as follow:

$H=f_{v} H_{v}+\left(1-f_{v}\right) H_{g}$

In Eq. (10), $H_{v}$ and $H_{g}$ are express as:

$H_{v}=\rho C p \frac{T_{v}-T_{a}}{r_{a}^{h}}$

$H_{g}=\rho C p \frac{T_{g}-T_{a}}{r_{a}^{a}+r_{a}^{s}}$

The land surface temperature was estimated using the AATSR measurement, and air temperature was collected by the eddy covariance measurement system. Definitely, the "point" observations have a limited regional representative. Therefore, the estimates of the air temperature from the eddy covariance system can be considered as the air temperature over the soil surface and vegetation. $r_{a}^{h}$ is the aerodynamic resistance between the corn canopy and the reference height at which the atmospheric data are measured $\left(\mathrm{m} \mathrm{s}^{-1}\right), r_{a}^{a}$ is the aerodynamic resistance to heat transfer between the point $Z_{0 M}+d\left(Z_{0 M}\right.$ : canopy roughness length for momentum, $d$ : displacement height) and the reference height $\left(\mathrm{m} \mathrm{s}^{-1}\right), r_{a}^{s}$ is the aerodynamic resistance to heat flow in the boundary layer immediately above the soil surface $\left(\mathrm{m} \mathrm{s}^{-1}\right)$. A summary of the expressions to estimate the aerodynamic resistance is shown in the Appendix.

\subsubsection{The soil heat flux over the vegetation canopy and the soil surface}

The instantaneous values of soil heat flux were approximately $10 \%$ of the net radiation under the bare soil and sparsely vegetated land surface at midday. For a wellvegetated land surface, these values might be less than $10 \%$. The soil heat flux could be adequately estimated by a linear function of crop height, with a value of $0.1 R_{n}$ for bare soil, and $0.05 R_{n}$ for a full wheat canopy covered land surface (Reginato et al., 1985). Based on Reginato's literature, and modified by vegetation index (Pang et al., 2004), we proposed a formula for soil heat flux estimates as follows

$G_{v}=(0.1-0.042 \times 2.5 \mathrm{NDVI}) R_{n}$

$G_{g}=0.1 R_{n}$

Finally, a complete and independent energy balance between the atmosphere and each component of the surface is established, from the assumption that all the fluxes act vertically.

\subsection{Daily ET}

Instantaneous $L E$ predictions need to be extrapolated to daily ET to be used in the monitoring of spatially distributed crop water use. Zhang and Lemeur (1995) use two different methods of converting instantaneous evapotranspiration into daily totals during the HAPEX-MOBILHY experiment in southwestern France. The first method is based on the assumption that the diurnal course of evapotranspiration is similar to that of solar irradiance and can be approximated by a sine function. The second method assumes that the evaporative fraction, defined as the ratio of the latent heat flux and the available energy flux, is constant during the daytime period. Hence, daily ET can be determined from the evaporative fraction and daily total available energy. Comparisons of estimated and measured daily ET indicated that both the methods are accurate for cloud-free days. However, the first method is preferable for the purpose of estimating regional ET using remote sensing data. There are 3 fields identified in the scene for which surface flux measurements were made during the HAPEX-MOBILHY experiment: a well irrigated oat field, a corn field with significant bare soil fraction and a pine forest. Our field site over the Chinese Loess Plateau is similar to HAPEX-MOBILHY experiment. So, the method recommended by Zhang and Lemeur (1995) is to be used in this study. Based on the assumption that the diurnal course of ET is similar to that of solar irradiance and can be approximated by a sine function, the daily ET can be obtained from one instantaneous measurement by the following expression

$\frac{L E_{d}}{L E}=\frac{2 N_{E}}{\pi \sin \left(\pi / N_{E}\right)}$

where $L E_{d}$ is daily ET; $N_{E}$ is daily effective sunlight hours. The ET value is very small around sunrise and sundown period, so effective ET time is the sunshine hours minus two. $L E$ is related to ET by $\mathrm{ET}=\frac{L E}{L \rho}$, where $\mathrm{ET}$ is the evapotranspiration $\left(\mathrm{m} \mathrm{s}^{-1}\right), L E$ is the latent heat flux $\left(\mathrm{W} \mathrm{m}^{-2}\right), L$ is the latent heat of vaporization $\left(\mathrm{J} \mathrm{kg}^{-1}\right), \rho$ is the density of water $\left(\mathrm{kg} \mathrm{m}^{-3}\right)$.

\section{Observation sites and data resources}

The Chinese Loess Plateau is situated in northwest China. It has inhomogeneous geographic features with elevation ranging from $1000 \mathrm{~m}$ to $1800 \mathrm{~m}$. With a summer-dominant rainfall pattern over the Loess Plateau, there is a need to evaluate the impact of ET on the crop soil-water balance and explore the consequent management implications. However, few land-atmosphere interaction studies have been conducted on the Loess Plateau because of its complex underlying surface. Based on improving the understanding of the loess mesa region land surface process, the LOess Plateau landatmosphere interaction pilot EXperiments (LOPEX05) was conducted from 15 July to 25 August near Pingliang city, Gansu Province of China (Wen et al., 2007). 


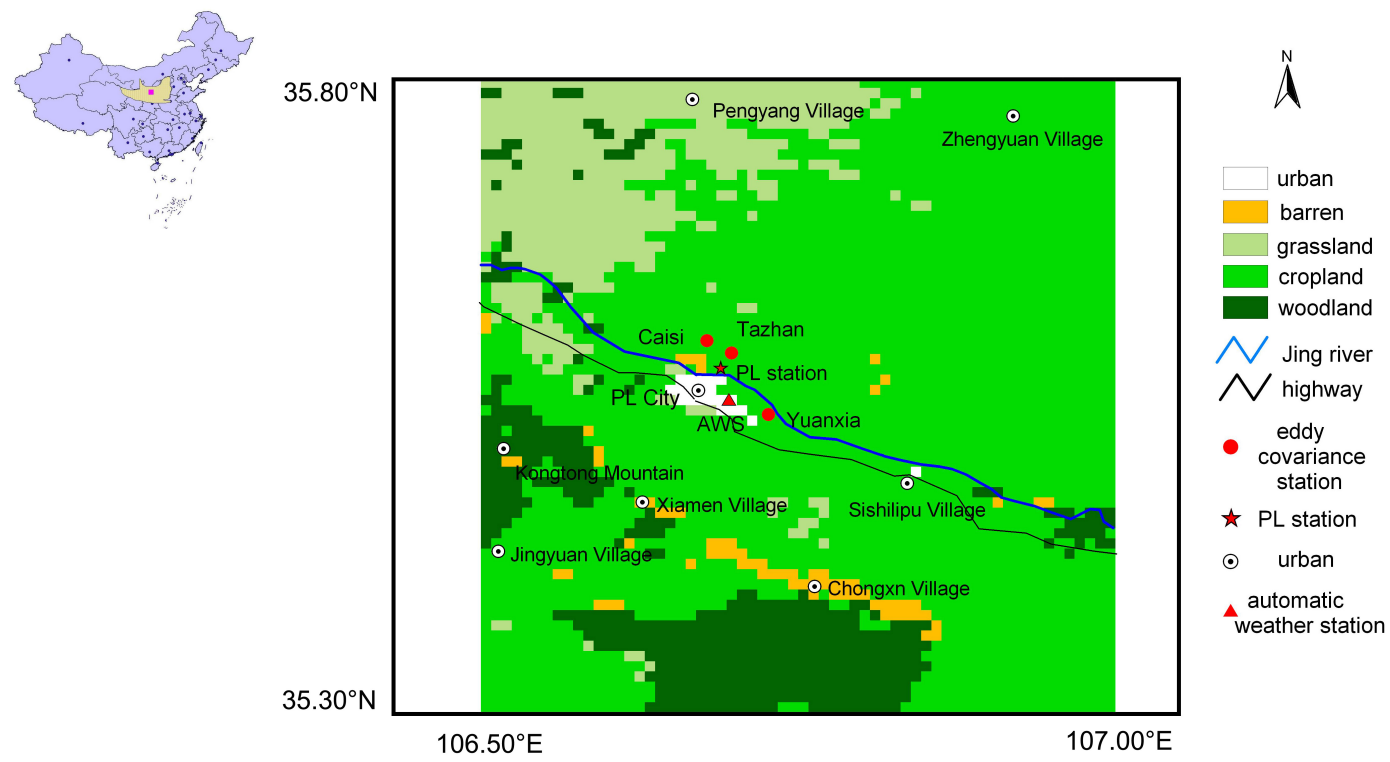

Fig. 2. Geographic location and landuse information of the LOPEXs study area.

\subsection{Observation sites}

The geographic locations of sampling fields are illustrated in Fig. 2, coordinates of the central point are $35.35^{\circ} \mathrm{N}$, $106.42^{\circ} \mathrm{E}$, with a $1592 \mathrm{~m}$ altitude above the sea. It has complex geomorphic features, consists of diverse landscapes including the loess mesa, lowlands, gullies, hills, the loess ridge, continuous knolls, dry gulches, flat ground, loess terraces, and other land surface types. The soil texture of the pilot experimental sampling fields is typical medium loam with a high proportion of silt, and the soil colour is characterised by yellow, brown and cinnamon (Yang and Shao, 2000). One major river runs through the region: the Yellow River, with the highest levels of silt anywhere in its reaches, flows through this region and carries away more than 1.4 billion tons of silt annually (Zhang, 2000).

The sites of eddy covariance systems and the micrometeorological instrumentation deployed in the Loess Plateau land surface process field experiment are also shown in Fig. 2. $\star$ represents the PL station (a village); • represents the eddy covariance system at the mesa bare soil surface and the mesa corn field; $\boldsymbol{\Delta}$ represents the automatic weather station installed at the edge of the mesa. The white part was Pingliang city, and grassland in the northwest on the map was Pengyang village. Chongxin village and the Mountain Kongtong covered by woodland were at the south and west of the map, respectively. A blue line represents the River Jing which is the anabranch of the Yellow River but dry perennial. A black line represents the thruway that is parallel with the watercourse of the River Jing.

The study area has a semi-arid climate. The average temperature is $6^{\circ}$, and the average annual precipitation is $510 \mathrm{~mm}$ (Wen et al., 2007). The main meteorological variables during the growing season of 2005 , were shown on Fig. 3a, b. The precipitation from the beginning of July to the beginning of September was $90.8 \mathrm{~mm}$, and the average relative humidity is $76 \%$. The daily mean air temperature $\left(T_{a}\right)$ and surface temperature $\left(T_{S}\right)$ ranged from 10.41-24.43 and $14.35-24.89^{\circ}$, respectively. The sharp decrease of daily mean $R_{n}$ corresponded well with $T_{a}$ and $T_{s}$.

The main crops in this area are winter wheat and summer corn. The entire growing season of winter wheat is from October to June of the next year. The corn growth period in this region is from July to September, whereas the most precipitation falls in the months July and August often causing severe droughts when irrigation is not sufficiently applied in time (Li et al., 2002). The water used for irrigation in this area is mainly from precipitation. During the growing time, the corn on the mesa begin to grow leaves in June and reach a maximum leaf area index (LAI) of around 4 in late July and early August (Fig. 2c), measured by LAI-2000 Plant Canopy Analyser. Vegetation water content (VWC), calculated by subtracting dry vegetation mass from the wet vegetation, ranged from $4.92-10.94 \mathrm{~kg} \mathrm{~m}^{-2}$ with the maximum value appearing at the beginning of August (Fig. 3c).

\subsection{Data recourses}

\subsubsection{Remote sensing data}

Many advances in instrumental design and processing algorithms, for earth observation purposes, have been achieved in the last decade. Those advances have enabled the launch of the ENVIronmental SATellite (ENVISAT) mission by the European Space Agency (ESA) in March 2002. Currently, ENVISAT is the ESA core mission for earth observation 


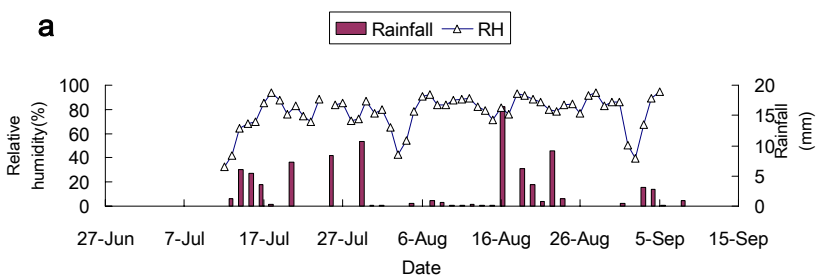

b

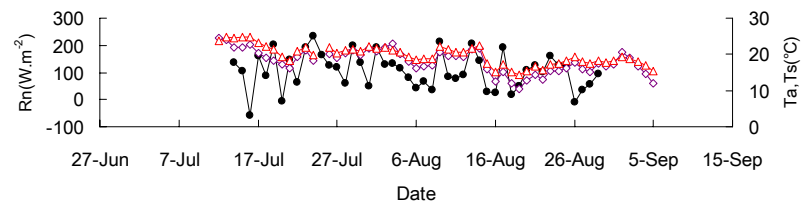

c

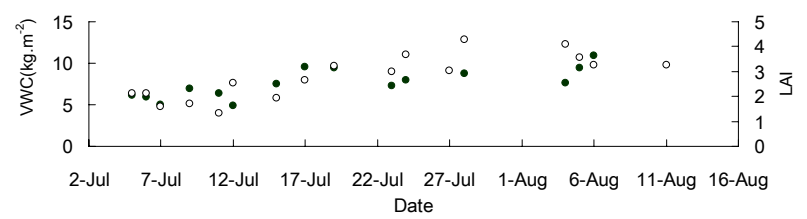

Fig. 3. Meteorological variables and the canopy structure parameters of the study area during the experimental period. (a) daily relative humidity (RH) and rainfall; (b) daily mean net radiation $\left(R_{n}\right)$, mean air temperature $\left(T_{a}\right)$ and mean surface temperature $\left(T_{S}\right)$; (c) leaf area index (LAI) and vegetation water content (VWC).

and different instruments were onboard ENVISAT. Medium Resolution Imaging Spectrometer Instrument (MERIS) and Advanced Along-Track Scanning Radiometer (AATSR) are two instruments onboard ENVISAT.

MERIS measures the solar radiation reflected by the earth surface in 15 spectral channels distributed within the visible and near-infrared spectral domain and offers a complete global coverage every 3 days. It is a multidisciplinary instrument operating in the $390 \mathrm{~nm}$ to $1040 \mathrm{~nm}$ spectral range. Pixel size is about $300 \mathrm{~m}$ for full spatial resolution data and about $1.2 \mathrm{~km}$ for reduced spatial resolution data. It was originally designed for marine applications and this predominance can also be used for land applications (Verstraete et al., 1999). The predominance of MERIS is its full resolution data $(300 \mathrm{~m})$ and is precise to monitor changes in optical variables. However, MERIS does not contain thermal band for land surface temperature estimate, so therefore, we deploy both MERIS and AATSR data in this investigation. The AATSR instrument is a self-calibrating infrared, nearinfrared and visible radiometer, using two highly stable onboard blackbody reference targets to calibrate the thermal channels and an opal diffuser for calibration of the visible and near-infrared channels. These data can be used to derive the surface albedo and surface temperature which are essential for the ET estimate of a particular interesting region. The AATSR was initially designed to provide regional sea surface temperature (SST). However, AATSR data are being used more frequently to obtain land surface temperature (LST) on a global scale.

With the daily ground observations, a relationship between the ground vegetation water content measurement and satellite remotely sensed indices was established and validated (Liu et al., 2007). But there are few researches on the estimation of ET over the Loess Plateau by using MERIS and AATSR data. Albedo, vegetation fraction and NDVI parameters data from MERIS and LST from AATSR were used in this study. Cloud fraction was very important during scene selection. Images with zero percent cloud were selected for the processing. There were only 3 days without cloud: 7, 11 and 27 June 2005. For the three days, both MERIS and AATSR data were available.

The surface albedo is derived by using the BEAM toolbox and MERIS data. The $R_{\mathrm{RED}}$ and $R_{\mathrm{NIR}}$ are the reflectance of the MERIS bands $8(0.681 \mu \mathrm{m})$ and $13(0.86 \mu \mathrm{m})$ for deriving NDVI, respectively. BEAM is a toolbox for viewing, analyzing and processing of remote sensing data. Originally developed to facilitate the utilization of image data from ENVISAT's optical instruments, BEAM now supports a growing number of other sensors such as MODIS, AVHRR, PRISM and CHRIS/Proba. The reflectance image, as well as the other atmospheric correction outputs, can be geometrically corrected. As the satellite data used in this study were from June 2005, no dust storms happened in this season, its aerosol consideration was similar to the one of the Mid-latitude Standard, so the Mid-latitude Standard aerosol profile was used for atmospheric correction in deriving land surface parameters, it will not give much error. For atmospheric correction over land, we can use the SMAC processor. The map projection processor, supplied with the BEAM software, can be triggered by user command in order to obtain the images geo-rectified into the latitude/longitude projection for converting L2 "Top-Of-Aerosols" reflectance to actual surface reflectance. Thus, the step of atmospheric correction of land surface reflectance in L2 data can be accomplished. The land surface temperature was calculated from $\mathrm{LST}=T_{11}+0.72+0.94\left(T_{11}-T_{12}\right)+0.25\left(T_{11}-T_{12}\right)^{2}$ by using the AATSR data, the values for the coefficients given by Coll et al. (2005) were used in this investigation.

\subsubsection{Ground observation data}

The loess mesa is agricultural lands, planted primarily with corn and winter wheat. After the harvest of winter wheat, the land surface becomes bare soil. Three field observation sites were installed, namely Tazhan, Yuanxia and Chaisi during the LOPEX05. The Tazhan and Yuanxia site represent the station at the mesa corn field, Chaisi site represents the station at the mesa bare soil surface. The net radiometer was derived from the measurements of a Kipp \& Zonen 
CNR-1 sensor mounted at $2.0 \mathrm{~m}$ height above ground level, the incoming and outgoing shortwave and long-wave radiation components were measured separately. The sensible heat, latent heat and carbon fluxes, as well as wind speed and direction were derived from measurements of a Campbell Scientific 3-D sonic anemometer, a Licor 7500 water vapour/carbon sensor positioned at $2.9 \mathrm{~m}$ height. The sampling frequency was $10 \mathrm{~Hz}$ for the eddy covariance system and $10 \mathrm{~s}$ for AWS. All data were stored as Campbell CR5000 memory. In addition, another Automatic Weather Station was installed at the edge of the mesa observing the air temperature, air humidity and wind speed. Besides these, the vegetation height, fraction, sunshine duration and weather conditions were measured and recorded during the experiment period. The measured sunshine duration was approximately $14 \mathrm{~h}$ during these separate days. The vegetation height was $90 \mathrm{~cm}, 120 \mathrm{~cm}$ and $190 \mathrm{~cm}$, average air temperature was $21.8^{\circ}, 23.1^{\circ}$ and $25.7^{\circ}$, respectively.

In the ground measurement, 7 representative cornfields were chosen for sampling VWC, LAI (Fig. 2c) and vegetation fractional coverage. The corn VWC, LAI and vegetation fractional coverage was measured every three days during the whole experimental period. The values of vegetation fractional coverage were $70 \%$ to $90 \%$. The air temperature was measured in mesa cornfield, mesa bare surface and lowland cornfield by instrument, and was used in calculating downward long-wave radiation and sensible heat flux. In the image, the cornfield was defined so that the value of vegetation fractional coverage was more than $70 \%$, in this area the values of air temperature was taken from our instrument.

Among the various Loess Plateau landscapes, the loess mesa, that the field experiment was conducted in, is characterized by a large flat mountain top area, where the width ranges from $10 \mathrm{~km}$ to $40 \mathrm{~km}$ in length. The eddy covariance instrumentation was oriented to the north, the predominant wind direction during the summer growing season. Unfavourable winds out of the south compromising the sonic measurements were flagged by the sensor system and discarded during post processing. Thus, the wind speed measured by the eddy covariance system represents the wind speed approximately over the whole territory and the satellite passes through the loess mesa at that moment.

All the EC system measurement data were routinely checked for quality assurance: various filtering techniques were applied in data pre-processing. Fluxes data were then examined at a ten-day basis, and extreme values and values greater than \pm 3 standard deviations were removed. For the missing values, daytime gaps were filled by linear interpolation between the nearest temporal measurements. Wen et al. (2007) pointed out that for the measurements in the mesa cornfield, the mesa fallow field and the lowland cornfield, the average energy budget closure deficit values were 0.5707 , 0.7334 , and 0.5020, respectively, in LOPEX04. This result was consistent with the results from ChinaFLUX and the International Network of Eddy Covariance Sites (FLUXNET).
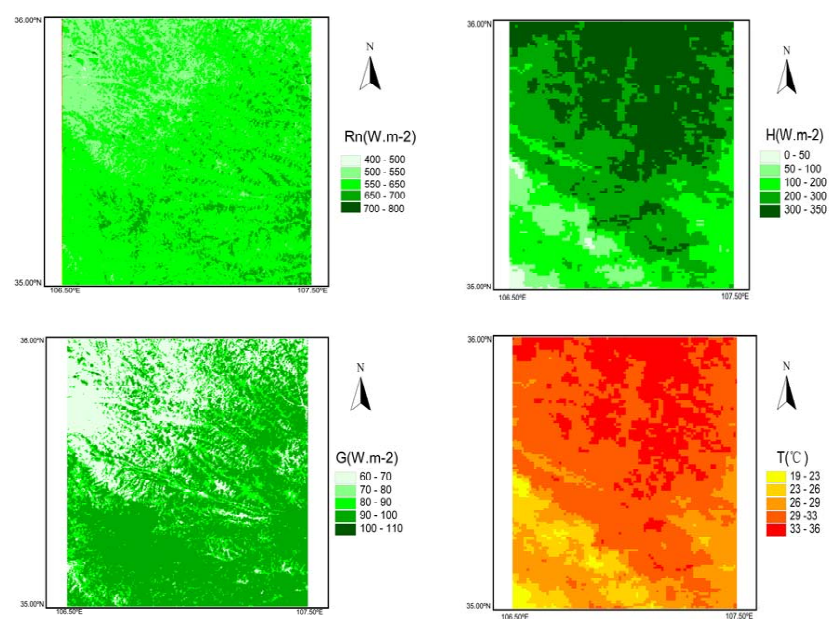

Fig. 4. Maps of instantaneous $R_{n}, H$ and $G$ estimates from MERIS and AATSR for 27 June 2005. Surface temperature $T_{S}$ retrieved from AATSR.

\subsection{Results and validation}

The specific routines for ET estimate are: firstly, vegetation fraction was estimated from the MERIS data, the land surface albedo was estimated by using BEAM and MREIS data, and the solar radiation is estimated from an existing algorithm (Wang, 1988). Secondly, the "split-window" algorithm was used to retrieve the surface temperature from the data of AATSR two infrared bands $(10.85 \mu \mathrm{m}$ and $12.50 \mu \mathrm{m})$. The estimated surface albedo and temperature was to partition to componential values of vegetation and soil surface by Eqs. (7-8) and Eqs. (11-12). Finally, with the aid of meteorological variables, the daily ET over the Loess Plateau heterogeneous region was estimated.

In Fig. 4, the land surface energy exchange was characterised by using ground and satellite remote sensing measurement data collected during LOPEXs. Compared with the land use map (Fig. 2), the net radiation fluxes were larger in the woodland and cropland than those in the sparse grassland and exposed bare soil surface. This was a reasonable result considering the radiative properties of the bare soil as opposed to those of the vegetation canopy; The soil heat flux was also larger in the woodland and cropland than in the sparse grassland and exposed bare soil surface because the exposed soil received more solar radiation than the vegetation canopy. In the Chinese Loess mesa, the net radiation fluxes were mainly consumed by latent heat flux than by sensible heat flux during the summertime (Liu et al., 2007). The sensible heat flux was larger in the sparse grassland and exposed bare soil surface compared to those in the woodland and cropland. Similar results were presented by Su et al. $(2008,2009)$. Land surface temperature was a little less in the woodland and cropland than in the sparse grassland and exposed bare soil surface. The lowest surface temperature was in the west part of the map named Kongtong Mountain. 
Table 1. Bias analysis of the remote sensing estimate and the eddy covariance system measurement.

\begin{tabular}{ccccccccccc}
\hline & Rn-b & Rn-c & G-b & G-c & H-b & H-c & LE-b & LE-c & ET-b & ET-c \\
\hline Bias & -62.6 & -73.3 & -26.3 & 6 & 112 & 30.1 & 19.3 & 64 & 0.37 & 0.17 \\
\hline
\end{tabular}

Bias analysis of the estimated data with the eddy covariance dataset (daytime). Where $E_{i}$ and $O_{i}$ are the satellite remote sensing estimate and ground measurement, respectively. -b means heat flux above the bare surface, -c means heat flux above the corn canopy, they are in energy unit $\mathrm{W} \mathrm{m}^{-2}$; ET-b and ET-c mean daily ET above the bare surface and the corn canopy, they are in unit $\mathrm{mm} \mathrm{s}^{-1}$.

Bias: $\mathrm{BIAS}=\sum_{i=1}^{n}\left(E_{i}-O_{i}\right) / n$.

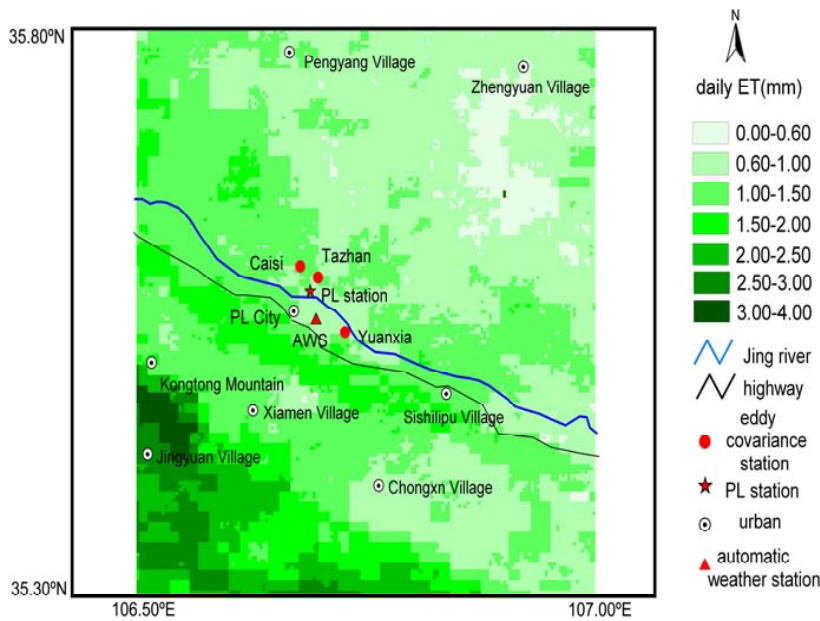

Fig. 5. Regional distribution of daily ET over the LOPEX study area on 27 June 2005.

The Fig. 5 shows the estimated ET decreases from south to north, which is corresponding to the land use map. The regions of higher value are concentrated at the Kongtong Mountain, and its ET values could reach more than $4.00 \mathrm{~mm}$, while in the Northeast regions, the values are less than $0.60 \mathrm{~mm}$. The values in the Chaisi site, the Tazhan site and the Yuanxia site are $0.75 \mathrm{~mm}, 1.98 \mathrm{~mm}$ and $2.25 \mathrm{~mm}$, respectively. The Chaisi site is situated in bare soil surface mesa, so it is different from the Tazhan site and the Yuanxia site. As the temperatures of three land surface types are significantly different, the near surface sensible heat exchange is weaker than that of grassland but stronger than that of woodland. The soil heat flux and surface latent flux are higher in the vegetable area, and the net radiation is lower than the bare soil. The corresponding value of ET over the mesa ranges is between the values of grassland and woodland.

The LOPEXs were conducted successively from 2004 to 2008 (Wen et al., 2009), it focused on different research topics every year. In this study, the collected MERIS and AATSR data were on 7, 11 and 27 June 2005, while the measurements of the eddy covariance system started from 12 July to 5 September 2005. In Loess Plateau, the crop planting date is according to the phenological calendar, the crop conditions of annual growing and reaping are almost the same date every year. Therefore, the measurements of two sets of eddy covariance system during 2006 were deployed to validate the instantaneous heat fluxes and daily ET estimated from remote sensing retrievals (in Fig. 6), the statistical bias are also listed in Table 1.

The remote sensing estimated latent heat flux shows a consistent relationship with simultaneous value of the ground eddy covariance measurement. The minimum and maximum relative errors of this approach are 9\% (Tazhan site, 7 June) and $46 \%$ (Chaisi site, 11 June). We can also draw conclusions that the error is smaller in high vegetation coverage area. Among the algorithms, the maximal bias is sensible heat flux in bare surface $\left(112 \mathrm{~W} \mathrm{~m}^{-2}\right)$ and the minimal bias is soil heat flux in corn canopy $\left(6 \mathrm{~W} \mathrm{~m}^{-2}\right)$. The above comparisons imply that the ET assessed by using MERIS and AATSR data is almost in accordance with the field observations. As the special geomorphology and inhomogeneity of the Loess Plateau mesa region and defects on the eddy covariance system, it inevitably leads to a reduction in the precision of flux. Brief explanations are listed as follow:

1. Oversimplification of the energy conservation model lead to error in this study. The land surface energy imbalance terms over the Chinese Loess Plateau mesa region corn field were large indeed, which implied that the magnitudes of the storage terms were considerable in the Loess Plateau Soil-Plant-Atmosphere Continuum (SPAC) system (Wen et al., 2007). Some issues remaining in the ET algorithm might also contribute to the differences between the ET estimates by the model and the tower ET observations.

2. The observation accuracy of the eddy covariance system is influenced by meteorological conditions. The maximal uncertainty of the eddy covariance system measurement can reach 20\% (Baldocchi et al., 2001). Moreover, in the semi-arid areas with sparse vegetation cover, the error in energy fluxes tends to be even higher, around 25\% (Were et al., 2007). In addition, within the data from different instruments are comparisons and calibrations during a prior period that was considered representative enough of the variability found in surface and climate variables at longer time scales (Wei et al., 2005). 

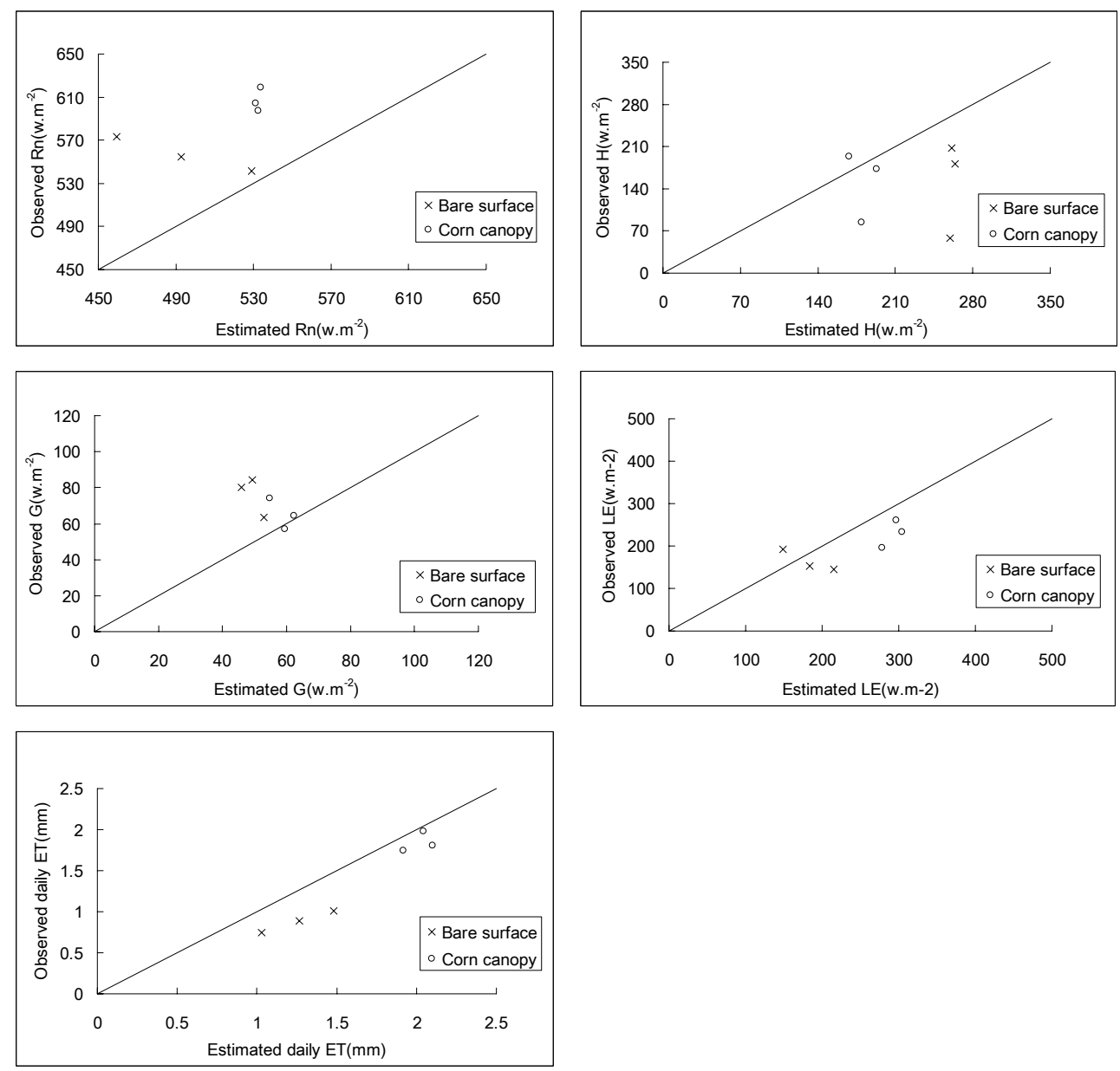

Fig. 6. Inter-compassion of remote sensing estimates and ground measured instantaneous heat fluxes and daily ET on 7, 11 and 27 June 2005.

\section{Conclusion and discussion}

The objective of this research was to present a simplified method for the ET estimates based on the land surface energy balance theory over the Loess Plateau. With the collected ground measurements and satellite remote sensing data during the LOPEXs, the land surface albedo, vegetation coverage fraction were derived from MERIS data, and the surface temperature was retrieved by using the "split-window" algorithm with the AATSR data. The instantaneous latent heat fluxes estimated from satellite remote sensing data were converted to daily ET by using an algorithm, and the results were validated by using the ground measurements.

In this simple algorithm for daily ET estimate, the required variables are land surface albedo, vegetation fraction, land surface temperature and relevant ground meteorological data. The estimated daily ET values were ranged from $0.6 \mathrm{~mm}$ to $4.0 \mathrm{~mm}$ in the study area. The average relative error was $16.0 \%$, and it was smaller in the area with high vegetation coverage. This implied that energy balance modelling is a feasible algorithm for irrigation management and monitoring crop water requirement in the arid regions. Further work is needed to improve the precision of land surface temperature retrieved from AATSR, implement sensitivity test for the ET under the different land surface characteristics.

\section{Appendix A}

\section{Summary of equations to estimate aerodynamic resistance}

The $r_{a}^{h}, r_{a}^{a}$ and $r_{a}^{s}$ are expressed as follows (Brutsaert, 1999): $r_{a}^{h}=\frac{\left[L n\left(\frac{Z_{U}-d}{Z_{O M}}\right)-\psi_{M}\left(\frac{Z_{U}-d}{L}\right)+\psi_{M}\left(\frac{Z_{O M}}{L}\right)\right]\left[L n\left(\frac{Z_{T}-d}{Z_{O H}}\right)-\psi_{H}\left(\frac{Z_{T}-d}{L}\right)+\psi_{H}\left(\frac{Z_{O H}}{L}\right)\right]}{k^{2} U}$

$r_{a}^{a}=\frac{\left[\operatorname{Ln}\left(\frac{Z_{U}-d}{Z_{O M}}\right)-\psi_{M}\right]\left[\operatorname{Ln}\left(\frac{Z_{T}-d}{Z_{O M}}\right)-\psi_{H}\right]}{k^{2} U}$

$r_{a}^{S}=\frac{1}{0.0025\left(T_{g}-T_{C}\right) 1 / 3+0.012 U_{S}}$ 
where $Z_{U}$ and $Z_{T}$ are the measurement heights (m) for wind speed, $u\left(\mathrm{~m} \mathrm{~s}^{-1}\right)$, and air temperature, respectively; $d$ is displacement height $(\mathrm{m}) ; Z_{O M}$ is the canopy roughness length for momentum $(\mathrm{m}), Z_{O H}$ is the canopy roughness length for heat $(\mathrm{m})$, and $K$ is the Von Karman constant $(\approx 0.41)$. $d$, $Z_{O M}$ and $Z_{O H}$ are estimated by simplified expressions as functions of canopy height $h(\mathrm{~m})$ (Garratt and Hicks, 1973),

$d=2 h / 3$

$Z_{O M}=h / 10$

$Z_{O H}=Z_{O M} / 7$

For details about the expressions to justify for the sparsely vegetated field, please reference to Su et al. (2001). The stability functions for heat, $\Psi_{H}$, and for momentum, $\Psi_{M}$, are obtained from Brutsaert (1999):

Unstable conditions,

$$
\begin{aligned}
\psi_{M}(y)= & \operatorname{Ln}(a+y)-3 b y^{1 / 3}+\frac{b a^{1 / 3}}{2} \operatorname{Ln}\left[\frac{(1+x)^{2}}{\left(1-x+x^{2}\right)}\right]+ \\
& 3^{1 / 2} b a^{1 / 3} \tan ^{-1}\left[(2 x-1) / 3^{1 / 2}\right]+\psi_{0} \\
\psi_{H}(y)= & {[(1-d) / n] \operatorname{Ln}\left[\left(c+y^{n}\right) / c\right] }
\end{aligned}
$$

Stable conditions,

$\psi_{M}(y)=\psi_{H}(y)=5 y$

Where $x=(y / a)^{1 / 3}, y=-(z-d) / L$, and $\psi_{0}$ is a constant of integration given by $\psi_{0}=\left(-\operatorname{Ln}(a)+3^{1 / 2} b a^{1 / 3} \pi / 6\right)$, The parameters $a, b, c, d$, and $n$ are assigned constant values of $0.33,0.41,0.33,0.057$, and 0.78 , respectively (Brutsaert, 1999). $L$ is the Monin-Obukhov length (m) and is expressed as

$$
L=\frac{-U_{*}^{3} \rho}{k g\left[\left(H / T_{a} C_{p}\right)+0.61 E\right]}
$$

where $u *$ is the friction velocity (From eddy covariance), $\rho$ is the air density $\left(\mathrm{kg} \mathrm{m}^{-3}\right), g$ is the acceleration of gravity $\left(\mathrm{m} \mathrm{s}^{-2}\right), C p$ is the air specific heat at constant pressure $\left(\mathrm{J} \mathrm{kg}^{-1} \mathrm{~K}^{-1}\right), H$ is the sensible heat flux (From eddy covariance), and $E$ is the rate of surface evaporation $\left(\mathrm{kg} \mathrm{m}^{-2} \mathrm{~s}^{-1}\right)$. Neutral conditions are firstly assumed, and the initial estimations of $H$ and $L E$ are used to obtain an initial value of $L$.

$U_{s}$ is the wind speed at height above the soil surface where the effect of soil surface roughness on the free wind movement can be neglected, $Z^{\prime}\left(\mathrm{m} \mathrm{s}^{-1}\right)$ (Sauer et al., 1995). This wind speed is determined assuming a logarithmic wind profile in the air space above the soil:

$$
U_{S}=U\left[\frac{\operatorname{Ln}\left(Z^{\prime} / Z_{0}^{\prime}\right)}{\operatorname{Ln}\left(Z_{U} / Z_{0}^{\prime}\right)-\psi_{M}}\right]
$$

where $Z_{0}^{\prime}$ is the soil roughness length. For details on the $Z^{\prime}$ and $Z_{0}^{\prime}$ formulations see Sauer et al. (1995).
Acknowledgements. Funding of the National Basic Research Program of China (Grant No. 2009CB421402) and the field station foundation of the Chinese Academy of Sciences, the Centurial Program sponsored by the Chinese Academy of Sciences (2004406), and supports from the LOPEXs research team and the equipment and logistical support provided by Pingliang Lightning and Hail Storm Experiment Station of The Chinese Academy of Sciences made possible of this research.

Edited by: Z. Su

\section{References}

Allen, R. G., Pereira, L. S., Raes, D., and Smith, M.: Crop evapotranspiration-Guidelines for computing crop water requirements-FAO Irrigation and drainage paper 56, FAO, Rome, 300, 1998.

Baldocchi, D., Falge, E., Gu, L., Olson, R., Hollinger, D., Running, S., Anthoni, P., Bernhofer, C., Davis, K., and Evans, R. FLUXNET: A New Tool to Study the Temporal and Spatial Variability of Ecosystem-Scale Carbon Dioxide, Water Vapor, and Energy Flux Densities, B. Am. Meteorol. Soc., 82, 2415-2434, 2001.

Bashir, M. A., Hata, T., Tanakamaru, H., Abdelhadi, A. W., and Tada, A.: Satellite-based energy balance model to estimate seasonal evapotranspiration for irrigated sorghum: a case study from the Gezira scheme, Sudan, Hydrol. Earth Syst. Sci., 12, 1129 1139, 2008, http://www.hydrol-earth-syst-sci.net/12/1129/2008/.

Bastiaanssen, W. G. M., Menenti, M., Feddes, R. A., and Holtslag, A. A. M.: A remote sensing surface energy balance algorithm for land (SEBAL). 1. Formulation, J. Hydrol., 212, 198-212, 1998.

Boegh, E.: Evaluating evapotranspiration rates and surface conditions using Landsat TM to estimate atmospheric resistance and surface resistance, Remote Sens. Environ., 79, 329-343, 2002.

Brutsaert, W.: Aspects of bulk atmospheric boundary layer similarity under free-convective conditions, Rev. Geophys., 37, 439451, 1999.

Chen, Y. H., Li, X. B., Li, J., and Shi, P. J.: A simple two-component structure model for daily evapotranspiration, Chinese Journal of Geomatics and Information Science of Wuhan University, 30, 1074-1079, 2005 (in Chinese).

Coll, C., Caselles, V., Galve, J. M., Valor, E., Niclòs, R., Sánchez, J. M., and Rivas, R.: Validation of land surface temperature derived from AATSR data at the Valencia test site, in: Proceedings of the MERIS (A) ATSR Workshop 2005 (ESA SP-597), Frascati, Italy, 26-30 September 2005, 29, 2005.

Glenn, E. P., Huete, A. R., Nagler, P. L., Hirschboeck, K. K., and Brown, P.: Integrating remote sensing and ground methods to estimate evapotranspiration, Crit. Rev. Plant Sci., 26, 139-168, 2007.

Gutman, G. and Ignatov, A.: The derivation of the green vegetation fraction from NOAA/AVHRR data for use in numerical weather prediction models, Int. J. Remote Sens., 19, 1533-1543, 1998.

Hoedjes, J. C. B., Chehbouni, A., Jacob, F., Ezzahar, J., and Boulet, G.: Deriving daily evapotranspiration from remotely sensed instantaneous evaporative fraction over olive orchard in semi-arid Morocco, J. Hydrol., 354, 53-64, 2008. 
Holtslag, A. A. M. and van Ulden, A. P.: A Simple Scheme for Daytime Estimates of the Surface Fluxes from Routine Weather Data, J. Appl. Meteorol., 22, 517-529, 1983.

Huang, J.: Discussions on the current situation of Chinese and Global Water Resources and countermeasures, Soft Science, 15, 53-55, 2001 (in Chinese).

Index, S. V.: Estimating Crop Water Deficit Using the Relation between Surface-Air Temperature and Spectral Vegetation Index, Remote Sens. Environ., 49, 246-263, 1994.

Jia, L., Li, Z. L., Menenti, M., Su, Z., Verhoef, W., and Wan, Z.: A practical algorithm to infer soil and foliage component temperatures from bi-angular ATSR-2 data, Int. J. Remote Sens., 24, 4739-4760, 2003.

Li, Z. L., Stoll, M. P., Zhang, R. H., Li, J., and Su, Z.: On the separate retrieval of soil and vegetation temperatures from ATSR data, Sci. China Ser. D, 44, 97-111, 2001.

Li, F. R., Gao, C. Y., Zhao, H. L., and Li, X. Y.: Soil conservation effectiveness and energy efficiency of alternative rotations and continuous wheat cropping in the Loess Plateau of northwest China, Agr. Ecosyst. Environ., 91, 101-111, 2002.

Liu, Y. Y., Wen, J., Wei, ZH. G., Li, Zh. Ch., Zhang, T. T., and Liu, R.,: Observation and analysis of the water and heat flux exchange between land surface and atmosphere over the Loess Plateau Mesa region, Plateau Meteorology, 26, 928-937, 2007 (in Chinese).

Liu, R., Wen, J., Zhang, T. T., Liu, Y. Y., and Li, Zh. Ch.,: Vegetation water content retrieved using MERIS and AATSR data over the Loess Plateau field experiment 2005, Chinese Journal of Remote sensing technology and application, 22, 371-381, 2007 (in Chinese).

Menenti, M., Jia, L., Li, Z. L., Djepa, V., Wang, J., Stoll, M. P., Su, Z., and Rast, M.: Estimation of soil and vegetation temperatures with multiangular thermal infrared observations: the HEIHE, SGP'97, IMGRASS, J. Geophys. Res., 106, 11997-12010, 2001.

McCabe, M. F., Kalma, J. D., and Franks, S. W.: Spatial and temporal patterns of land surface fluxes from remotely sensed surface temperatures within an uncertainty modelling framework, Hydrol. Earth Syst. Sci., 9, 467-480, 2005,

http://www.hydrol-earth-syst-sci.net/9/467/2005/.

McVicar, T. R. and Jupp, D. L. B.: Estimating one-time-of-day meteorological data from standard daily data as inputs to thermal remote sensing based energy balance models, Agric. Forest Meteorol., 96, 219-238, 1999.

Overgaard, J., Rosbjerg, D., and Butts, M. B.: Land-surface modelling in hydrological perspective: A review, Biogeosciences, 3, 229-241, 2006, http://www.biogeosciences.net/3/229/2006/.

Pang, Z., Fu, J., Li, J., and Xiao, Q.: Remote sensing model for estimating evapotranspiration based on energy balance, Advances in water science, 15, 364-369, 2004 (in Chinese).

Priestley, C. H. B. and Taylor, R. J.: On the assessment of surface heat flux and evaporation using large-scale parameters, Mon. Weather Rev., 100, 81-92, 1972.

Reginato, R. J., Jackson, R. D., and Pinter, P.: Evapotranspiration calculated from remote multispectral and ground station meteorological data, Remote Sens. Environ., 18, 75-89, 1985.

Ryu, Y., Kang, S., Moon, S. K., and Kim, J.: Evaluation of land surface radiation balance derived from moderate resolution imaging spectroradiometer (MODIS) over complex terrain and heteroge- neous landscape on clear sky days, Agric. Forest Meteorol., 148, 1538-1552, 2008.

Sauer, T. J., Norman, J. M., Tanner, C. B., and Wilson, T. B.: Measurement of heat and vapor transfer coefficients at the soil surface beneath a maize canopy using source plates, Agric. Forest Meteorol., 75, 161-189, 1995.

Seckler, D., Barker, R., and Amarasinghe, U.: Water scarcity in the twenty-first century, Int. J. Water Resour. D., 15, 29-42, 1999.

Spittlehouse, D. L. and Black, T. A.: Evaluation of the bowen ratio/energy balance method for determining forest evapotranspiration, Atmos. Ocean, 18, 98-116, 1980.

Su, Z., Pelgrum, H., and Menenti, M.: Aggregation effects of surface heterogeneity in land surface processes, Hydrol. Earth Syst. Sci., 3, 549-563, 1999, http://www.hydrol-earth-syst-sci.net/3/549/1999/.

Su, Z., Schmugge, T., Kustas, W. P., and Massman, W. J.: An evaluation of two models for estimation of the roughness height for heat transfer between the land surface and the atmosphere, J. Appl. Meteorol., 40, 1933-1951, 2001.

Su, Z.: The Surface Energy Balance System (SEBS) for estimation of turbulent heat fluxes, Hydrol. Earth Syst. Sci., 6, 85-100, 2002, http://www.hydrol-earth-syst-sci.net/6/85/2002/.

Su, Z., Yacob, A., Wen, J., Roerink, G., He, Y., Gao, B., Boogaard, H., and van Diepen, C.: Assessing relative soil moisture with remote sensing data: theory, experimental validation, and application to drought monitoring over the North China Plain, Phys. Chem. Earth, 28, 89-101, 2003.

Su, Z., Timmermans, W., Gieske, A., Jia, L., Elbers, J. A., Olioso, A., Timmermans, J., Van Der Velde, R., Jin, X., and Van Der Kwast, H.: Quantification of land-atmosphere exchanges of water, energy and carbon dioxide in space and time over the heterogeneous Barrax site, Int. J. Remote Sens., 29, 17, 5215-5235, 2008.

Su, Z., Timmermans, W. J., van der Tol, C., Dost, R., Bianchi, R., Gómez, J. A., House, A., Hajnsek, I., Menenti, M., Magliulo, V., Esposito, M., Haarbrink, R., Bosveld, F., Rothe, R., Baltink, H. K., Vekerdy, Z., Sobrino, J. A., Timmermans, J., van Laake, P., Salama, S., van der Kwast, H., Claassen, E., Stolk, A., Jia, L., Moors, E., Hartogensis, O., and Gillespie, A.: EAGLE 2006 Multi-purpose, multi-angle and multi-sensor in-situ and airborne campaigns over grassland and forest, Hydrol. Earth Syst. Sci., 13, 833-845, 2009, http://www.hydrol-earth-syst-sci.net/13/833/2009/.

Verstraete, M. M., Pinty, B., and Curran, P. J.: MERIS potential for land applications, Int. J. Remote Sens., 20, 1747-1756, 1999.

Wang, B. Zh.: The measurement and standard of solar radiation energy, Science Publisher Press, Beijing, China, 1988.

Wei, Zh. G., Wen, J., Lü, Sh. H., Chen, Sh. Q., Ao, Y. H., and Yang, L.: The pilot experiment of land-atmosphere interaction and characters of land surface energy budget over the Loess Plateau, Plateau Meteorology, 24, 545-555, 2005 (in Chinese).

Wen, J., Wei, Zh. G., LU, Sh. H., Chen, Sh. Q., Ao, Y. H., and Yang, L.: Autumn daily characteristics of land surface heat and water exchange over the Loess Plateau Mesa in China, Adv. Atmos. Sci., 24, 301-310, 2007.

Wen, J., Wang, L., and Wei, Z. G.: An overview of the LOess Plateau mesa region land surface process field EXperiment series (LOPEXs), Hydrol. Earth Syst. Sci., 13, 945-951, 2009, http://www.hydrol-earth-syst-sci.net/13/945/2009/. 
Were, A., Villagarcía, L., Domingo, F., Alados-Arboledas, L., and Puigdefábregas, J.: Analysis of effective resistance calculation methods and their effect on modelling evapotranspiration in two different patches of vegetation in semi-arid SE Spain, Hydrol. Earth Syst. Sci., 11, 1529-1542, 2007,

http://www.hydrol-earth-syst-sci.net/11/1529/2007/.

Yang, W. Z. and Shao, M. A.: Study of soil water on the Loess Plateau, Science Press, Beijing, China, 35-85, 2000 (in Chinese).
Zhang, L. and Lemeur, R.: Evaluation of daily evapotranspiration estimates from instantaneous measurements, Agric. Forest Meteorol., 74, 139-154, 1995.

Zhang, Z. H.: Nine Curved Yellow River and Long Ranged Sand: Yellow River and the Chinese Loess Plateau, Tsinghua University Press, Beijing, China, 33-61, 2000 (in Chinese).

Zhang, Ch. Ch., Wang, X. Y. and Shao, J. L.: Estimated evapotranspiration based on NOAA data in the Yellow River Delta, Resour. Sci., 27, 86-91, 2005 (in Chinese). 